\title{
A Preliminary Investigation on Partial Rootzone Drying (PRD) Effects on Grapevine Performance, Nitrogen Assimilation and Berry Composition
}

\author{
P.G. du Toit ${ }^{{ }^{*}}$, P.R. Dry ${ }^{2}$ and B.R. Loveys ${ }^{2}$ \\ (1) School of Agriculture and Wine, University of Adelaide, Waite Campus, PMB1, Glen Osmond, South Australia, 5064 \\ (2) CSIRO, Plant Industry, Hartley Grove, Urrbrae, South Australia, 5064
}

Submitted for publication: August 2002

Accepted for publication: September 2003

Key words: Partial rootzone drying, water use efficiency, berry size, stomatal conductance, nitrate reductase, Vitis vinifera

\begin{abstract}
Partial rootzone drying (PRD) is an irrigation management technique designed to reduce water use in grapevines without a decline in yield, thereby increasing water use efficiency (WUE). Experiments consisted of field-grown Cabernet Sauvignon, where the PRD grapevines were irrigated with half the amount of water as control grapevines, and Shiraz, where the PRD grapevines received the same amount of water as control grapevines. PRD treatments showed no significant differences in yield or berry composition at harvest, except that PRD grapevines that received half the amount of water had significantly smaller berries than control grapevines. Cabernet Sauvignon PRD grapevines receiving half the amount of water as control grapevines showed a $34 \%$ reduction in main shoot growth and up to a $74 \%$ reduction in lateral shoot growth. Shoot growth was inhibited to a lesser extent in Shiraz PRD grapevines receiving the same amount of water, with a $20 \%$ reduction in main shoot.growth and a $33 \%$ reduction in lateral shoot growth. PRD also significantly reduced stomatal conductance in Cabernet Sauvignon on average by $31 \%$ and $16 \%$ in Shiraz. Nitrate reductase (NR) activity in grapevine leaves was significantly lowered in response to PRD, irrespective of the amount of water applied. The reduction in NR activity was closely correlated with the development of the PRD cycle and the associated reduction in stomatal conductance.
\end{abstract}

Partial rootzone drying (PRD) is an irrigation management technique developed in grapevines with a consistent feature that there is no reduction in yield even though the amount of irrigation water is substantially reduced in comparison to normal irrigation practices (Dry et al., 2001), thereby increasing water use efficiency (WUE). PRD requires the frequent irrigation of approximately half of the root system while the other half is left to dry (Fig. 1). After a certain period of time the 'wet' and 'dry' zones are alternated, allowing the former 'wet' zone to dry while the 'dry' zone is irrigated (Dry \& Loveys, 1999). Two dripper lines per grapevine row with offset drippers that can be operated independently can achieve the desired wetting pattern. PRD irrigation can start when normal irrigation commences and, depending on type of soil and climatic conditions, the alternation of 'wet' and 'dry' zones would typically occur on a ten-to fifteen-day cycle.

The PRD system probably relies on hormonal signals originating from the roots in response to low soil water potentials within the 'dry' zone. Much evidence has been accumulated that drying roots are the origin of abscisic acid (ABA), which is involved in regulating stomatal aperture (Zhang \& Davies, 1990; Davies \& Zhang, 1991; Davies et al., 1994; Comstock, 2002). Normally the closure of stomata in response to drying soil conditions serves to protect leaf tissue from excessive loss of moisture, thereby conserving water by reducing transpiration. In the PRD system the grapevine is given a false sense of waterstress, because one root zone is constantly exposed to low soil water potentials, producing $\mathrm{ABA}$ and sending a signal to the above-ground organs. The observed effects of ABA in above-ground organs due to PRD are a reduction in shoot growth and partial stomatal closure (Dry \& Loveys, 1999). Without alternating the 'wet' and 'dry' sides, i.e. wetting only one side of the grapevine while the other side continues to dry out, has shown that stomatal conductance and shoot growth rate will start to recover after a certain period of time (Dry \& Loveys, 1999). It has been found (Loveys et al., 2000; Stoll et $a l ., 2000 \mathrm{~b}$ ) that this recovery correlated with a reduced production of ABA in the 'dry' roots. It was therefore suggested that a long-term effect on stomatal conductance and shoot growth in grapevines is only possible if the signal originating from the 'dry' side can be sustained. By alternating the 'wet' and 'dry' sides, it was possible to maintain a long-term response (Dry et al., 2001) and it became clear that a continuous chemical signal or a certain concentration of the signal is necessary to maintain a physiological response.

PRD has the effect of controlling vegetative growth in grapevines, which may lead to a reduced canopy density and improved grapevine balance (Dry et al., 2001). While other irrigation management techniques such as regulated deficit irrigation (RDI) may reduce vigour, they are often accompanied by a penalty in yield (Matthews \& Anderson, 1988, 1989; Goodwin \& Jerie, 1992; Dry et al., 2001).

Vegetative growth and development are limited by nitrogen availability more than any other nutritional factor (Crawford \& Glass, 1998). The absorption of nitrate $\left(\mathrm{NO}_{3}{ }^{-}\right)$and ammonium $\left(\mathrm{NH}_{4}{ }^{+}\right.$) by plants allows them to form numerous nitrogenous com-

*Corresponding author: E-mail address: gerhard_dutoit@yahoo.com

Acknowledgements: We would like to acknowledge Winetech SA for financial support, as well as additional project support from the Australian Grape and Wine Research Development Corporation (GWRDC) and the University of Adelaide and Commonwealth Scientific \& Industrial Research Organisation (CSIRO) - Plant Industry for support and use of facilities. 


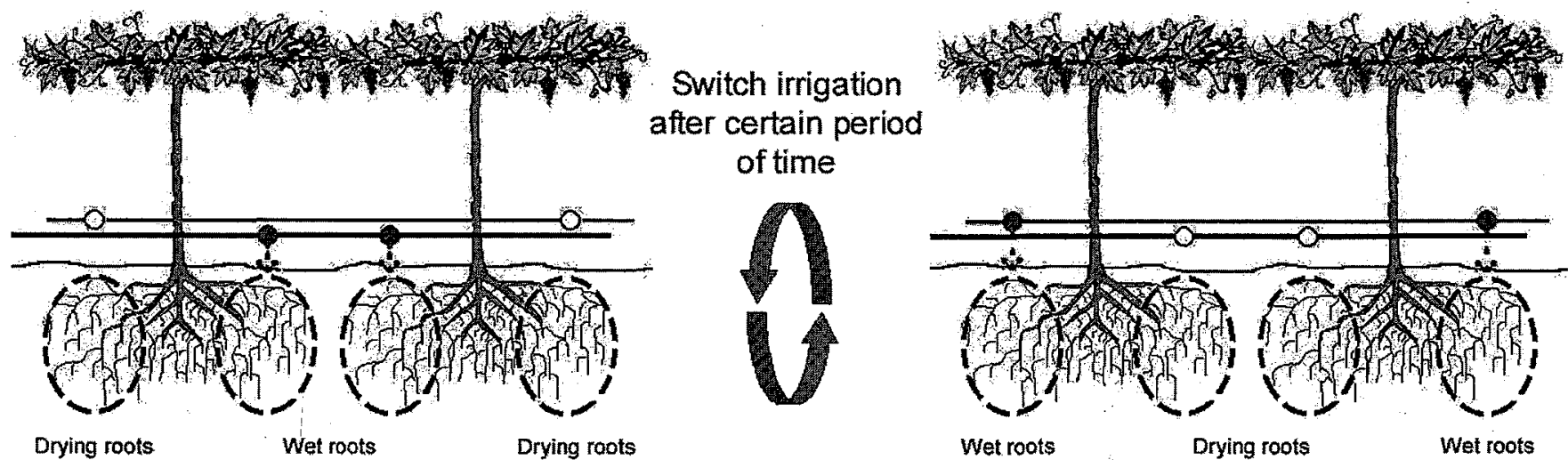

FIGURE 1

Implementation of partial rootzone drying.

pounds, mainly proteins, essential to growth and metabolism. Central to the assimilation of inorganic $\mathrm{N}$ to organic nitrogenous compounds is the energy-dependent and substrate-inducible enzyme nitrate reductase (NR) (Gojon et al., 1991; Lewis et al., 2000). However, its activity can be altered by several environmental, hormonal or metabolic factors (Huber et al., 1992; De Cires et al., 1993). Equally important is the glutamine synthase/glutamate synthase (GS/GOGAT) cycle (Givan, 1979; Roubelakis-Angelakis \& Kliewer, 1992), thought to be the most important process in the production of amino acids in grapevine leaves and roots. Our study therefore started with an investigation into the activities of NR and glutamine synthase (GS) as a measure of nitrogen assimilation in PRD grapevines. This article reports on the effect of $\mathrm{PRD}$ on certain aspects of the nitrogen assimilation process as well as PRD effects on grapevine performance under field conditions and associated effects on berry composition.

\section{MATERIALS AND METHODS}

\section{PRD irrigation}

To illustrate how the PRD system was maintained, soil water content was monitored by means of the Enviroscan ${ }^{\circledR}$ soil moisture sensor system (Sentek Pty Ltd, Adelaide, South Australia). The irrigation regimes of the control and $P R D$ (PRD received the same amount of water as control) during the 2000/01 season are shown in Figures 2 and 3. Data were suimmed for the top $700 \mathrm{~mm}$, because that is where most of the roots were distributed within the soil profile. Probes were situated on either side of a control grapevine and a PRD grapevine within the wetting zones, 300 $\mathrm{mm}$ from the trunk. Measurements were taken every 20 minutes at $100,200,300,400,500,700$ and $1000 \mathrm{~mm}$ depths and automatically recorded by a solar-powered logger. In order to maintain an adequate water supply to both control and PRD grapevines, the soil water content of the 'wet' zone was never allowed to fall below a certain soil water content referred to as refill point 1 (Figs. 2 and 3). The PRD cycle was achieved by switching the wetting zones as soon as the soil water content in the 'dry' zone reached refill point 2 . Refill point 2 is an arbitrary value where the slope of the graph of the soil water content in the 'dry' zone flattens to indicate a low rate of soil water extraction.
As shown in Figure 3, the 'wet' zone of the PRD system was irrigated when the soil water content reached refill point 1 . Refill point 1 corresponded roughly to the refill point calculated in a normal irrigation regime and therefore the 'wet' zone constituted a normal irrigation regime. PRD Cabernet Sauvignon grapevines received half the amount of irrigation water of control grapevines and PRD Shiraz received the same amount of irrigation water as control grapevines. Control grapevines received irrigation through one dripper line with two $2 \mathrm{~L} / \mathrm{h}$ drippers $300 \mathrm{~mm}$ on either side of the trunk. PRD grapevines received irrigation from two separate dripper lines with alternating $2 \mathrm{~L} / \mathrm{h}$ drippers for Cabernet Sauvignon and $4 \mathrm{~L} / \mathrm{h}$ drippers for Shiraz respectively (Fig. 1), thereby successfully irrigating both control cultivars and PRD Shiraz grapevines with $4 \mathrm{~L} / \mathrm{h}$ and PRD Cabernet Sauvignon with $2 \mathrm{~L} / \mathrm{h}$ irrigation water. Cabernet Sauvignon control grapevines received a total of $107 \mathrm{~mm} / \mathrm{ha}$ of irrigation, while PRD grapevines received a total of $53 \mathrm{~mm} / \mathrm{ha}$. Shiraz control and PRD grapevines both received a total of $107 \mathrm{~mm} / \mathrm{ha}$ of irrigation. Irrigation amounts are based on total vineyard surface and therefore the amounts in $\mathrm{mm}$ applied to the actual wetted zone were considerably higher. Total effective rainfall (above $5 \mathrm{~mm} /$ day) for the irrigation period was $62 \mathrm{~mm}$, ranging over a total of only 5 days during the PRD irrigation period. Rainfall events were too few to have had any effect on PRD treatments.

\section{Plant material}

Experimental grapevines had a vertically shoot positioned (VSP) trellis system and were situated in the Coombe vineyard (Waite Campus, Adelaide, South Australia) planted in 1991 to a spacing of $3 \mathrm{~m} \times 1.8 \mathrm{~m}$. The soil type is classified as 'Dr2.23 Hard Pedal Red Duplex' with $8 \%$ clay content at $0-110 \mathrm{~mm}$ and $60 \%$ clay content at 300-690 mm (Litchfield, 1951). All grapevines were own-rooted and spur pruned. Experimental design for both cultivars consisted of a randomised block design with two treatments, control and PRD irrigation, and seven replicates within one row. Each plot consisted of three grapevines and data were only collected from the centre grapevine, thereby leaving 2 buffer grapevines between each treatment. Grapevines were pruned to leave 30 nodes $/ \mathrm{kg}$ winter pruning mass and bunch thinning was done in 2000 before flowering, aiming for 60 bunches per grapevine. 


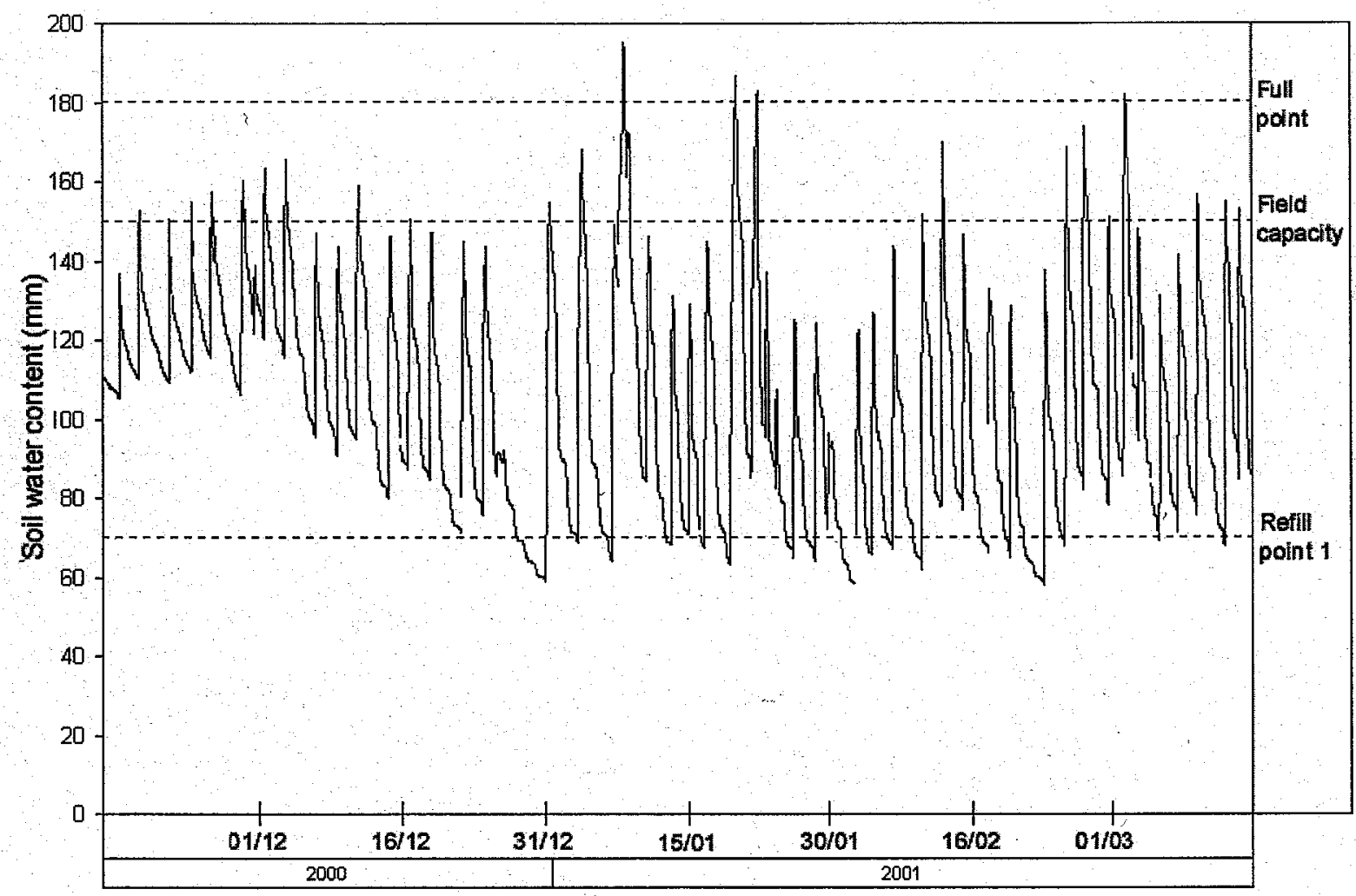

FIGURE 2

Soil water content $(\mathrm{mm})$ of control irrigation measured at 0-700 $\mathrm{mm}$ depth by EnviroSCAN ${ }^{\oplus}$ during the $2000 / 01$ season.

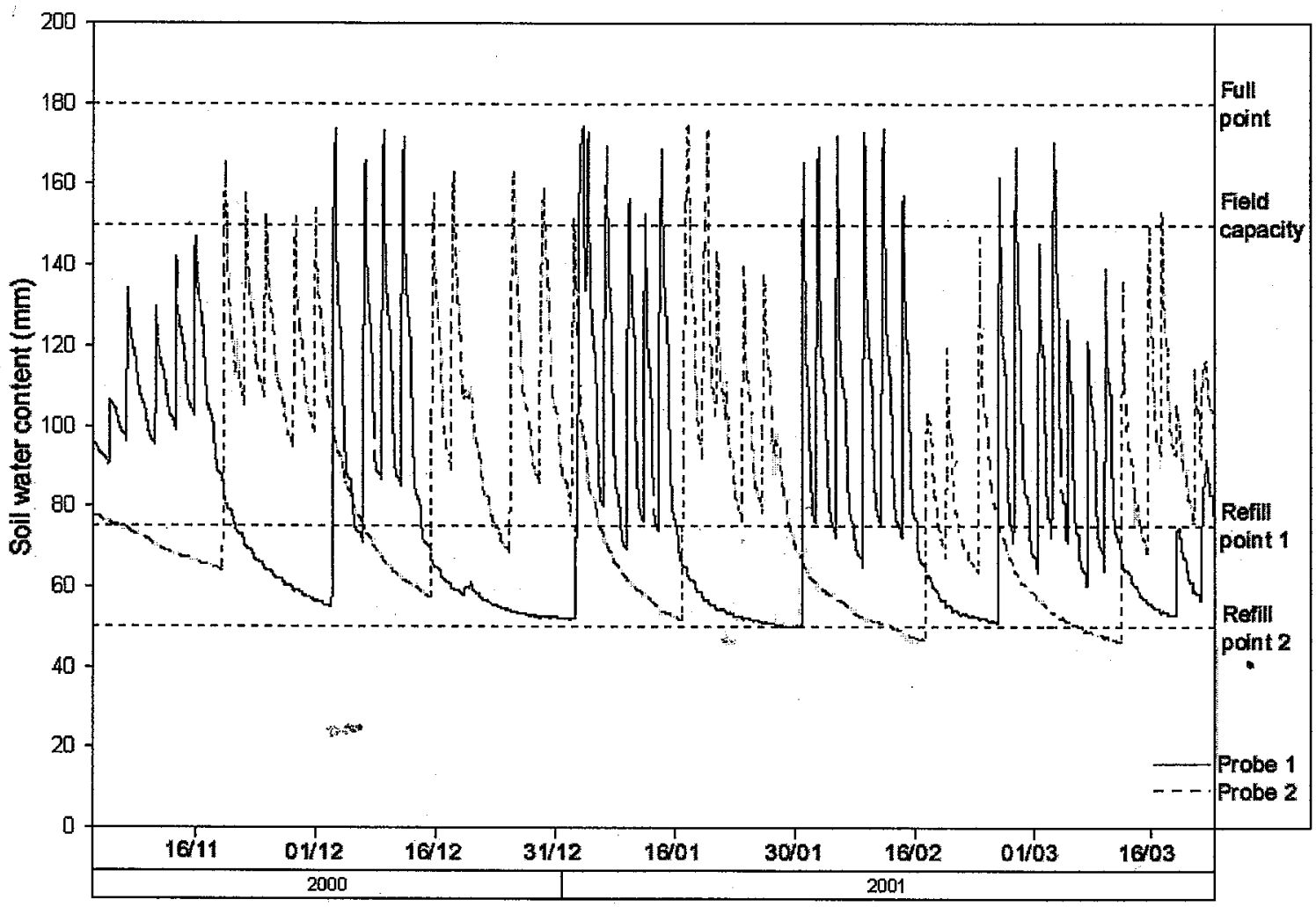

FIGURE 3

Soil water content (mm) of PRD irrigation measured at 0-700 $\mathrm{mm}$ depth by EnviroSCAN ${ }^{\oplus}$ during the $2000 / 01$ season. 


\section{General methods and calculations}

Grapevines were harvested and pruned by hand on 9 March and 20 July respectively. Bunches and canes were counted and weighed on-site. Berry mass was calculated for each plot by weighing a random sample of 200 berries. Juice ${ }^{\circ} \mathrm{Brix}$ and $\mathrm{pH}$ were assessed after the sample was crushed and filtered. Stomatal conductance of leaves was determined using a portable porometer (Delta-T AP4, Delta-T Devices, Cambridge, UK) according to manufacturer's recommendations. Measurements were conducted during cloudless periods on fully matured and fully sun-exposed leaves selected at random at the same time of the day (12:00 to 14:00).

Shoot measurements started when PRD irrigation commenced at the end of November until active shoot growth stopped in the beginning of January. Shoot growth rate was measured by selecting a reference node at five to seven nodes below the shoot tip. It was labelled and the distance between the reference node and the shoot tip was measured at intervals of seven days. Shoot growth rate $(\mathrm{cm} /$ day) was calculated as the average increase in shoot length since the previous measurement. When a shoot stopped growing, that shoot was discarded from the pool and measurements continued on only the remaining shoots. Therefore shoot growth rate was representative of actively growing shoots. In some cases shoots were replaced after the shoot tip was damaged by wind or machinery.

Leaf water potential was measured on fully matured leaves between 09:00 and 10:00. For each measurement a leaf was wrapped in a polyethylene bag and removed with a single cut across the petiole with a razor blade. Xylem water potential was measured by placing the leaf into a pressure bomb (Scholander et al., 1965) attached to a nitrogen gas cylinder. Pressure was increased slowly until exudation of xylem sap from the cut end of the petiole was observed.

Rainfall aside, WUE is an index of the efficiency with which irrigation water reaches the grapevine and the efficiency with which water is transpired in fixing carbon. In this study WUE will be defined as the amount of crop harvested per unit of irrigation water applied ( $t / \mathrm{ML}$ ). In the Australian environment a WUE for premium red cultivars can range between a value of 4 (hot, dry regions, e.g. Sunraysia) and 13 (cooler regions, e.g. Adelaide and McLarenVale) (Dry et al., 2001).

Statistical analyses were done using both the Microsoft ${ }^{\circledR}$ Excel 2000 and $\mathrm{SAS}^{\circledast}$ statistical analysis software. Results comparing multiple groups of data were analysed using ANOVA and Student T-tests were used to determine significant differences between groups. Significance levels are indicated by P-values.

\section{Analytical methods}

Soluble sugars, proline, proline analogs and betaines were analysed as described by Naidu (1998). Leaves and berries were frozen in liquid nitrogen and powdered with a mortar and pestle. A sample of $300 \mathrm{mg}$ of powdered tissue was then placed in a centrifuge tube and $3 \mathrm{~mL}$ of ice-cold methanol:chloroform:water (MCW; 60:25:15) added. After adding $5 \mu \mathrm{mol}$ of D-sorbitol as internal standard, the contents were inverted for 5 minutes. The MCW emulsion was broken by the addition of $3 \mathrm{~mL}$ water and the contents of the tube were centrifuged at $10,000 \mathrm{~g}$ for $10 \mathrm{~min}$ at $4^{\circ} \mathrm{C}$. The clear upper methanol-water (MW) phase was removed and dried. After being redissolved in $500 \mu \mathrm{L}$ of water, the osmolytes were passed through a SepPak $\mathbf{C}_{18}$ cartridge (Waters Corporation) and injected into a High-Pressure Liquid Chromatography system (Hewlett Packard LC1100), passing through a Waters Sugar-Pak I HPLC column maintained at $80^{\circ} \mathrm{C}$. Column eluate passed into a diode array detector scanning every second from 190 to $400 \mathrm{~nm}$ at an interval of $1.2 \mathrm{~nm}$. Optimum absorbancy was attained at $192 \mathrm{~nm}$. Standards of soluble sugars (sucrose, glucose, fructose) and other osmolytes (alanine betaine, glycine betaine, hydroxy-N-methyl-proline, methyl proline and proline) were analysed in the same way to generate standard curves over a 10 -fold concentration range. The mobile phase was bacteria-free water containing $50 \mathrm{mg} / \mathrm{L} \mathrm{Ca-EDTA}$. To ensure that the mobile phase was gas free, it was passed through an in-line degasser. Flow rate was maintained at $0.6 \mathrm{~mL} / \mathrm{min}$.

The activity of glutamine synthase (GS) was determined by the method described by Lin \& Kao (1996). Leaves were harvested approximately one month before harvest and consisted of five sun-exposed mature leaves within the first basal five leaves per plot. Plant tissue was homogenised with $10 \mathrm{mM}$ Tris- $\mathrm{HCl}$ buffer (pH 7.6), containing $1 \mathrm{mM} \mathrm{MgCl}_{2}, 1 \mathrm{mM}$ EDTA and $1 \mathrm{mM} 2-$ mercaptoethanol in a chilled pestle and mortar. The homogenate was then centrifuged at $15000 \mathrm{~g}$ for $30 \mathrm{~min}$ and the supernatant used for the enzyme assay. The whole extraction procedure was carried out at $4^{\circ} \mathrm{C}$. GS assay was done on the supernatant by the method described by Oaks et al. (1980). The reaction mixture contained in a final volume of $1 \mathrm{~mL}, 80 \mu \mathrm{mol}$ Tris-HCL buffer, $40 \mu \mathrm{mol} \mathrm{L-glutamic} \mathrm{acid,} 8 \mu \mathrm{mol}$ ATP, $24 \mu \mathrm{mol} \mathrm{MgSO}_{4}$ and 16 $\mu \mathrm{mol} \mathrm{NH}_{2} \mathrm{OH}$ (final $\mathrm{pH} 8.0$ ). Reaction was started by the addition of the enzyme extract and, after incubation for $30 \mathrm{~min}$ at $30^{\circ} \mathrm{C}$, the reaction was stopped by the addition of $2 \mathrm{~mL} 2.5 \%(\mathrm{w} / \mathrm{v})$ $\mathrm{FeCl}_{3}$ and $5 \%(\mathrm{w} / \mathrm{v})$ trichloroacetic acid in $1.5 \mathrm{M} \mathrm{HCl}$. The mixture was centrifuged at $3000 \mathrm{~g}$ and the absorbance of the supernatant was read at $540 \mathrm{~nm}$. One unit of GS activity is defined as $1 \mu \mathrm{mol} \mathrm{L}$-glutamate $\gamma$-monohydroxamate formed per min.

Nitrate reductase (NR) activity was assayed in leaves by the method described by Hunter \& Ruffner (1997). Leaves were harvested approximately one month before harvest roughly every second day for seven intervals. Harvests consisted of two samples of each plot and each sample consisted of three fully sun-exposed mature leaves within the first five basal leaves. After the removal of leaf veins, leaves were cut into $4 \mathrm{~mm}^{2}$ disks. Representative samples of leaves $(0.2 \mathrm{~g})$ were immediately infiltrated under vacuum in pre-cooled $50 \mathrm{~mL}$ Erlenmeyer flasks containing $5 \mathrm{~mL}$ $0.1 \mathrm{M} \mathrm{KNO}_{3}$ and $5 \mathrm{~mL} 0.1 \mathrm{M}$ phosphate $\left(\mathrm{Na}_{2} \mathrm{HPO}_{4} .12 \mathrm{H}_{2} \mathrm{O}-\right.$ $\mathrm{KH}_{2} \mathrm{PO}_{4}$ ) buffer at $\mathrm{pH} 7.5$. In controls, $\mathrm{KNO}_{3}$ was substituted with water. The infiltration of the tissue comprised repetitive $(5 \times 30$ sec) removal of oxygen by vacuum and replacement with $\mathrm{N}_{2}$. After infiltration, $\mathrm{N}_{2}$ was bubbled into the incubation medium for $60 \mathrm{sec}$. Flasks were then sealed with rubber stoppers, wrapped in aluminium foil and incubated with gentle shaking in a water bath for $1 \mathrm{~h}$ at $40^{\circ} \mathrm{C}$. After incubation the flasks were vortexed for 10 $\mathrm{sec}$ and $1 \mathrm{~mL}$ aliquots removed for nitrite determination. Nitrite was estimated by the addition of $1 \mathrm{ml} 1 \%(\mathrm{w} / \mathrm{v})$ Sulphanilamide in $1.75 \mathrm{M} \mathrm{HCl}, 1 \mathrm{~mL} 0.01 \%$ (w/v) $\mathrm{N}$-(1-naphthyl)ethylenediamine dihydrochloride and $5 \mathrm{~mL} \mathrm{H}_{2} \mathrm{O}$. Absorbance was read at $540 \mathrm{~nm}$ after $30 \mathrm{~min}$. The NRA is expressed as nmol nitrite produced per gram fresh weight per hour. 


\section{RESULTS AND DISCUSSION}

\section{Grapevine performance affected by PRD}

PRD grapevines showed no significant reductions in yield for the season of 2000/01 relative to control (Table 1). Bearing in mind that grapevines were bunch-thinned and pruned to a level of 30 nodes $/ \mathrm{kg}$ pruning mass, WUE for Cabernet Sauvignon and Shiraz at the site was within normal expectations for the region. PRD treatment on Cabernet Sauvignon grapevines (half the mount of irrigation water) increased the WUE by $89 \%$ (Table 1) compared to control. PRD Shiraz grapevines irrigated with the same amount of water as control grapevines had higher yields over the two-year period, also increasing WUE (Table 1). However, the increase in yield and WUE in Shiraz may not be attributed to PRD but rather to higher bunch numbers per grapevine.

Differences in bunch counts at harvest (Table 1) may be due to losses incurred with summer hedging or ineffective bunch thinning. A significant difference was found in berry size of Cabernet Sauvignon grapevines receiving half the amount of water. PRD grapevines had significantly $(\mathrm{P} \leq 0.05)$ smaller berries than control grapevines but more berries per bunch, resulting in comparable bunch masses and yield. It was not clear if the smaller berries on PRD grapevines were a direct consequence of irrigation treatment or an indirect effect of berry number per bunch. Smaller berries may have significantly positive effects on berry and wine quality, because the skin surface per unit berry mass or volume would be increased (Singleton, 1972). Singleton (1972) found that even a $10 \%$ decrease in average berry size without a change in berry composition produced red wine with recognizable and therefore important increases in aroma, colour, tannin and quality. PRD had no significant influence on berry composition with respect to ${ }^{\circ} \mathrm{Brix}, \mathrm{pH}$ (Table 1) or soluble sugars and osmolytes (Table 2).

PRD-treated Cabernet Sauvignon had significantly higher total soluble solids ( ${ }^{\circ} \mathrm{Brix}$ ) early in maturity (Fig. 4). However, differences disappeared with further berry development until a week before harvest. At this stage no discernable difference could be found between treatments. PRD-treated Cabernet Sauvignon at harvest, however, had slightly higher ${ }^{\circ}$ Brix. The reasons for this are unclear. For Shiraz juice ${ }^{\circ}$ Brix where PRD received the same amount of irrigation water as the control, there were no significant differences between treatments at any stage from véraison until harvest (Fig. 5).

\section{TABLE 1}

Performance data of Cabernet Sauvignon (PRD received half the amount of irrigation water as control) and Shiraz (PRD received the same amount of irrigation water as control). (n.s. $=$ not significant; * = significant $(\mathrm{P} \leq 0.05)$.

\begin{tabular}{|c|c|c|c|c|c|c|c|c|}
\hline & \multicolumn{4}{|c|}{ Cabernet Sauvignon } & \multicolumn{4}{|c|}{ Shiraz } \\
\hline & Control & PRD & $\% \mathrm{Di}$ & & Control & PRD & \%Diff. & \\
\hline Yield (kg/grapevine) & 3.94 & 3.69 & -6 & n.s. & 5.53 & 6.89 & 25 & $*$ \\
\hline Juice ${ }^{\circ}$ Brix & 24.4 & 25.4 & 4 & n.s. & 26.8 & 27.3 & 2 & n.s. \\
\hline Juice $\mathrm{pH}$ & 3.53 & 3.45 & -2 & n.s. & 3.54 & 3.53 & 0 & n.s. \\
\hline Main shoot growth (cm/week) & 3.16 & 2.08 & -34 & * & 12.86 & 10.34 & -20 & n.s. \\
\hline Lateral shoot growth (cm/week) & 2.70 & 0.70 & -74 & n.s. & 12.14 & 8.18 & -33 & n.s. \\
\hline Shoot no/grapevine & 55 & 62 & 13 & n.s. & 59 & 75 & 27 & $*$ \\
\hline Bunch no/grapevine & 73 & 65 & -11 & n.s. & 75 & 88 & 18 & $*$ \\
\hline Bunch mass (g) & 58.2 & 58.8 & 1 & n.s. & 74.0 & 78.9 & 7 & n.s. \\
\hline Berry mass (g) & 0.98 & 0.87 & -11 & * & 1.17 & 1.16 & -1 & n.s. \\
\hline Berry no/grapevine & 59 & 67 & 14 & n.s. & 63 & 68 & 8 & n.s. \\
\hline Irrigation (ML/ha set to harvest) & 1.07 & 0.53 & -50 & & 1.07 & 1.07 & 0 & \\
\hline WUE (t/ML) & 7.4 & 13.9 & 89 & & 10.3 & 12.9 & 25 & \\
\hline
\end{tabular}

TABLE 2

Effect of PRD on berry soluble sugars and osmolytes ( $\mu \mathrm{Mol} / \mathrm{g}$ fresh mass) of field-grown Cabernet Sauvignon and Shiraz (harvest 2001). All comparisons are not significant.

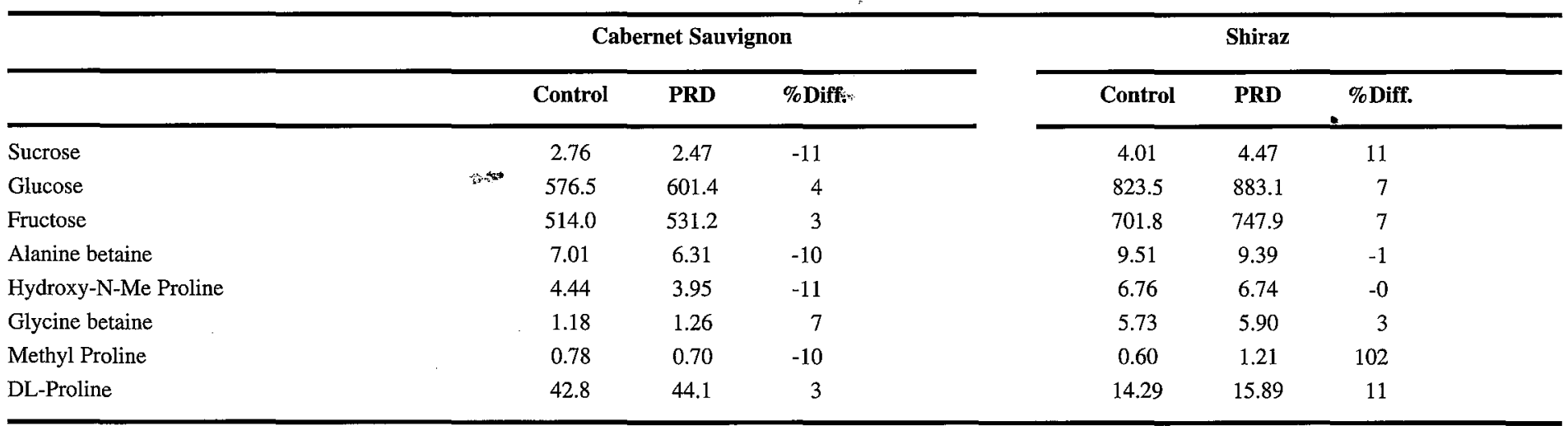




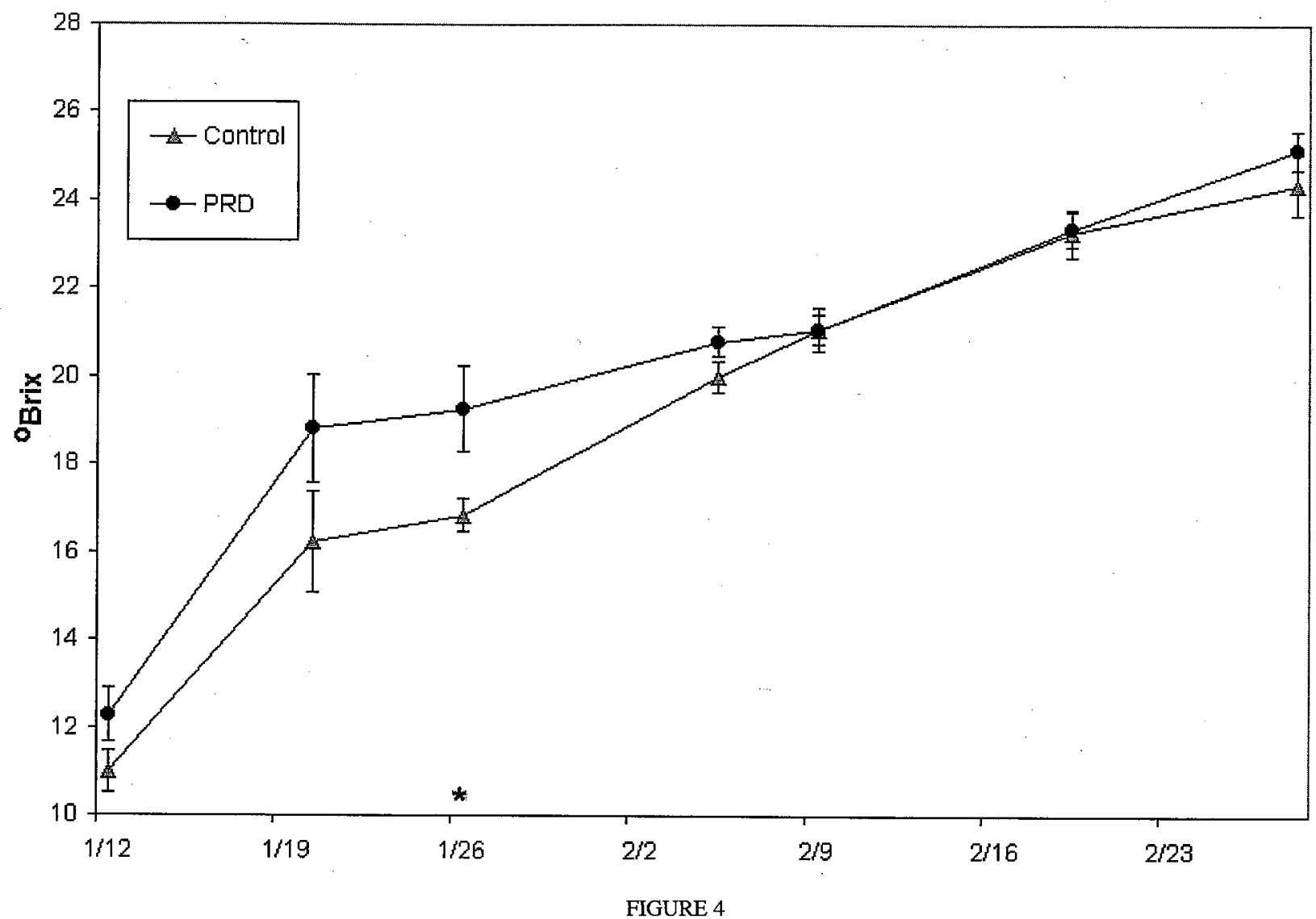

Juice ${ }^{\circ}$ Brix of Cabernet Sauvignon (2000/01 season). PRD received half the amount of water as control. Vertical bars indicate standard errors of the average. $*=$ significantly different $(\mathrm{P}<0.05)$.

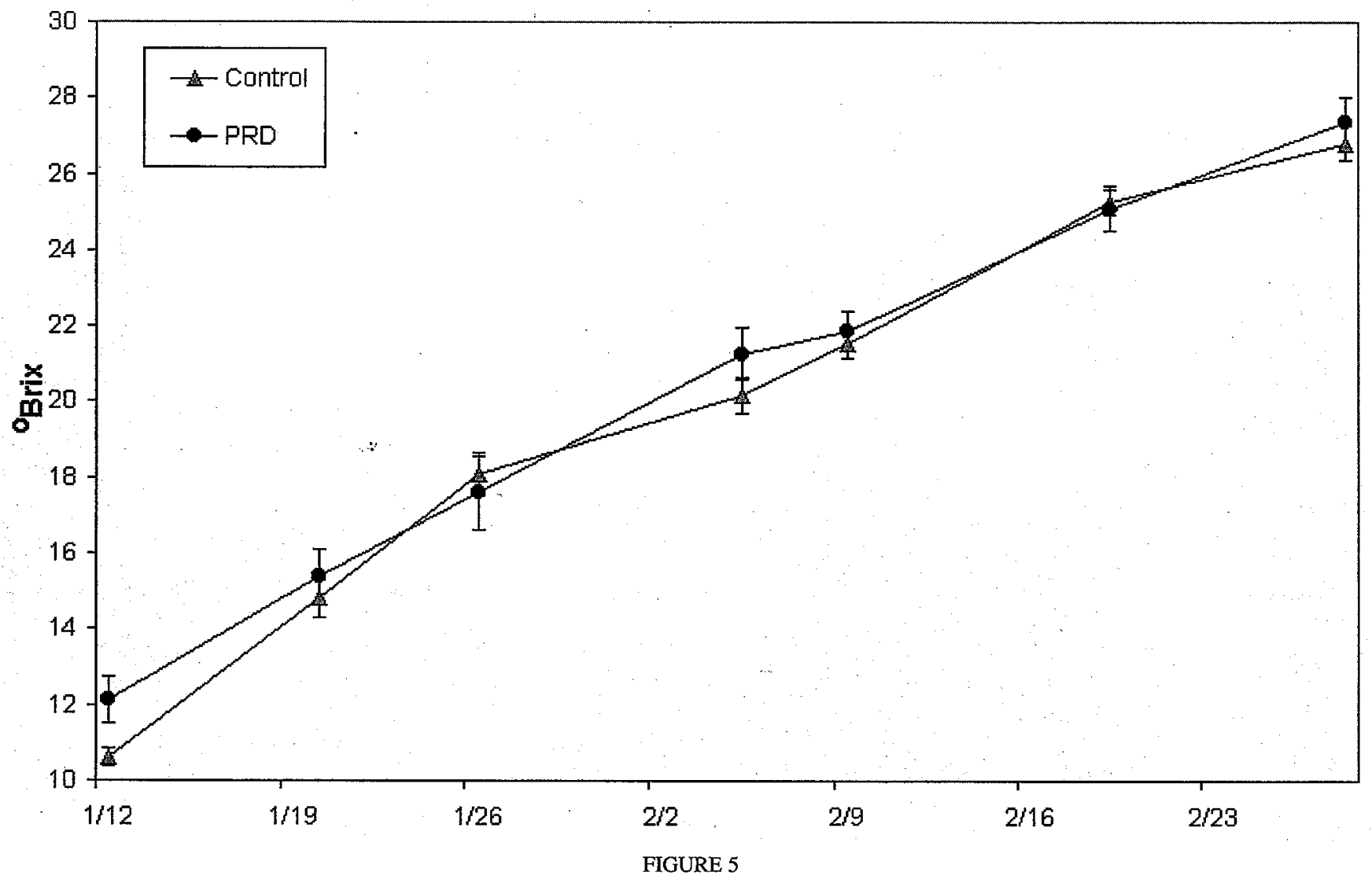

Juice ${ }^{\circ}$ Brix of Shiraz (2000/01 season). PRD received the same amount of water as control. Vertical bars indicate standard errors of the average. 
PRD significantly decreased shoot growth rate (Fig. 6) when irrigated with half the amount of water as the control, amounting to a $34 \%$ decrease in main shoot growth (Table 1) and a 74\% decrease in lateral shoot growth. Although not significant (Fig. 7), Shiraz PRD grapevines receiving the same amount of water as control grapevines showed a $20 \%$ decrease (Table 1) in main shoot growth rate and a $33 \%$ decrease in lateral shoot growth. These findings are in accordance with earlier reports by Loveys et al. (2000). PRD therefore decreased grapevine shoot growth independently of the amount of water applied and predominantly affected lateral shoot growth. Lateral shoot growth plays an important role in increasing canopy density and leaf area. Earlier reports (Loveys et al., 2000; Dry et al., 2001) found significant decreases in leaf area mainly due to a reduction in lateral shoot growth.

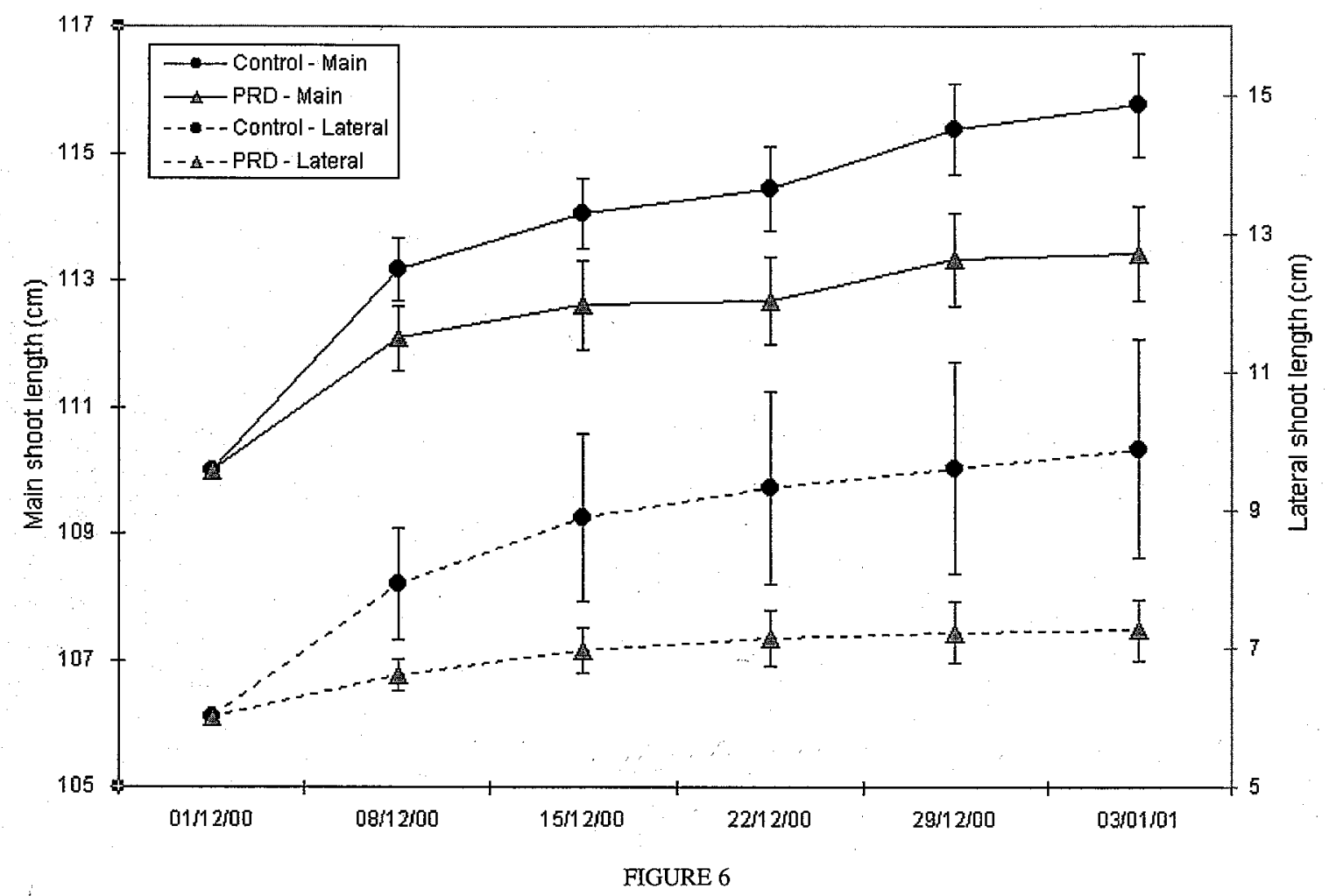

Shoot length of Cabernet Sauvignon (2000/01 season). PRD received half the amount of water as control. Vertical bars indicate standard errors of the average.

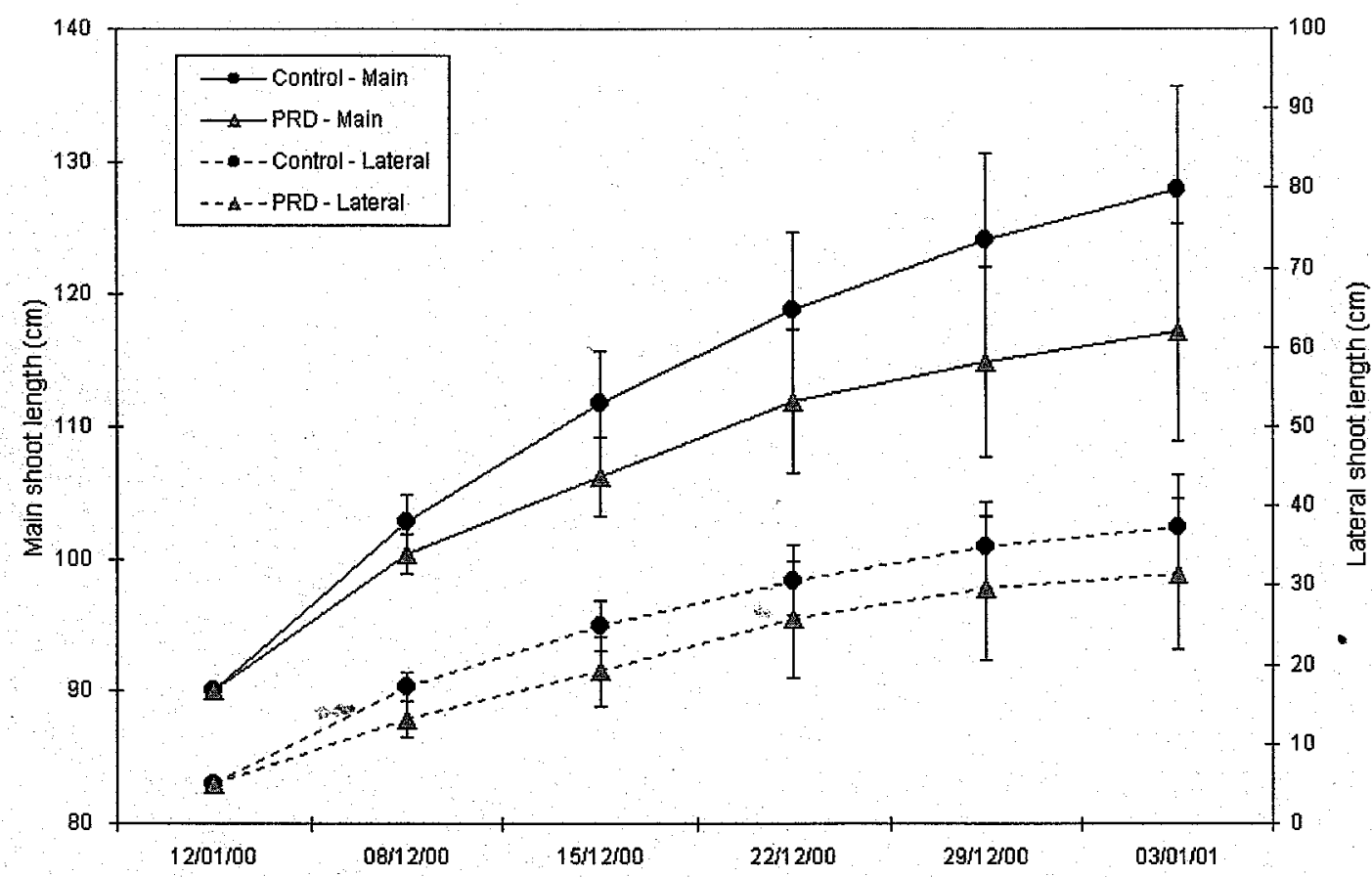

FIGURE 7

Shoot length of Shiraz (2000/01 season). PRD receiving the same amount of water as control. Vertical bars indicate standard errors of the average. 


\section{Grapevine physiology affected by PRD}

Earlier PRD experiments with tomato (Davies et al., 2000) and grapevines in pot and field experiments (Loveys et al., 2000; Stoll et al., 2000b) have shown that PRD treatment has no detrimental effect on leaf water potentials. By contrast, deficit irrigation of grapevines may significantly reduce leaf water potential relative to well-watered controls (Matthews \& Anderson, 1988). Grapevines exposed to severe water stress may exhibit mid-morning leaf water potentials in the order of $-1.5 \mathrm{MPa}$ to $-2.3 \mathrm{MPa}$ (Dundon \& Smart, 1984). Investigations into plant water status during this experiment indicated that PRD had no significant effect on mid-morning leaf water potentials of field-grown Cabernet Sauvignon or Shiraz (data not shown) similar to previous findings. Control leaves of both cultivars had an average of -0.94 Mpa; while PRD-treated Cabernet Sauvignon and Shiraz leaves averaged -0.98 and $-0.92 \mathrm{MPa}$ respectively.

PRD grapevines showed significantly $(\mathrm{P} \leq 0.05)$ lower stomatal conductance on most sample days when irrigated with half the amount of water (Fig. 8) and with the same amount of water as control (Fig. 9). PRD significantly reduced average stomatal conductance by $31 \%$ and $16 \%$ in Cabernet Sauvignon and Shiraz respectively. Therefore, the reduced stomatal conductance appears to be mainly due to a PRD effect and not simply a reduction in amount of water applied.

Investigation into enzyme activity of the GS/GOGAT cycle revealed that GS activity was not significantly influenced in response to PRD (Table 3) even in Cabernet Sauvignon PRD grapevines that received half the amount of irrigation water as control grapevines.

NR activity compared closely to values found by Hunter \& Ruffner (1997) in basal leaves of Cabernet Sauvignon. Leaf NR in both Cabernet Sauvignon and Shiraz, however, showed a sig-
TABLE 3

GS activity measured in leaves of field-grown Cabernet Sauvignon and Shiraz (2000/01 season). GS activity is defined as $\mu \mathrm{mol} \mathrm{L-}$ glutamate $\gamma$-monohydroxamate/min.

\begin{tabular}{lccc}
\hline & Control & PRD & P \\
\hline Cabernet Sauvignon & 0.268 & 0.233 & 0.416 \\
Shiraz & 0.137 & 0.123 & 0.560 \\
\hline
\end{tabular}

nificant decrease in activity in response to PRD (Figs 10 and 11). The NR activity was investigated over the period of a single PRD cycle. NR activity in response to PRD followed the development of the PRD cycle. Although the effect of PRD was less pronounced in Shiraz (Fig. 11), differences were still significant and the trend was still obvious.

At the beginning of the PRD cycle, where one rooting zone was kept wet and the 'dry' side had just started to dry, the difference in NR activity between control and PRD grapevines was small but significant. As the PRD cycle continued, the magnitude of the difference in NR activity increased, indicating a growing inhibition of NR in PRD grapevines. During these stages NR activity correlated closely with stomatal conductance (Fig. 12). By the end of the PRD cycle the magnitude of the difference in NR activity between control and PRD grapevines had diminished (Figs 10 and 11), and the correlation between NR and stomatal conductance was not as strong (Fig. 13). Earlier studies by Dry and Loveys (1999) and Dry et al. (2000) showed a PRD-induced reduction in both stomatal conductance and assimilation rate $(\mathrm{Pn})$. PRD may, through its effect on stomatal conductance, have a direct effect on NR activity due to lowered Pn.

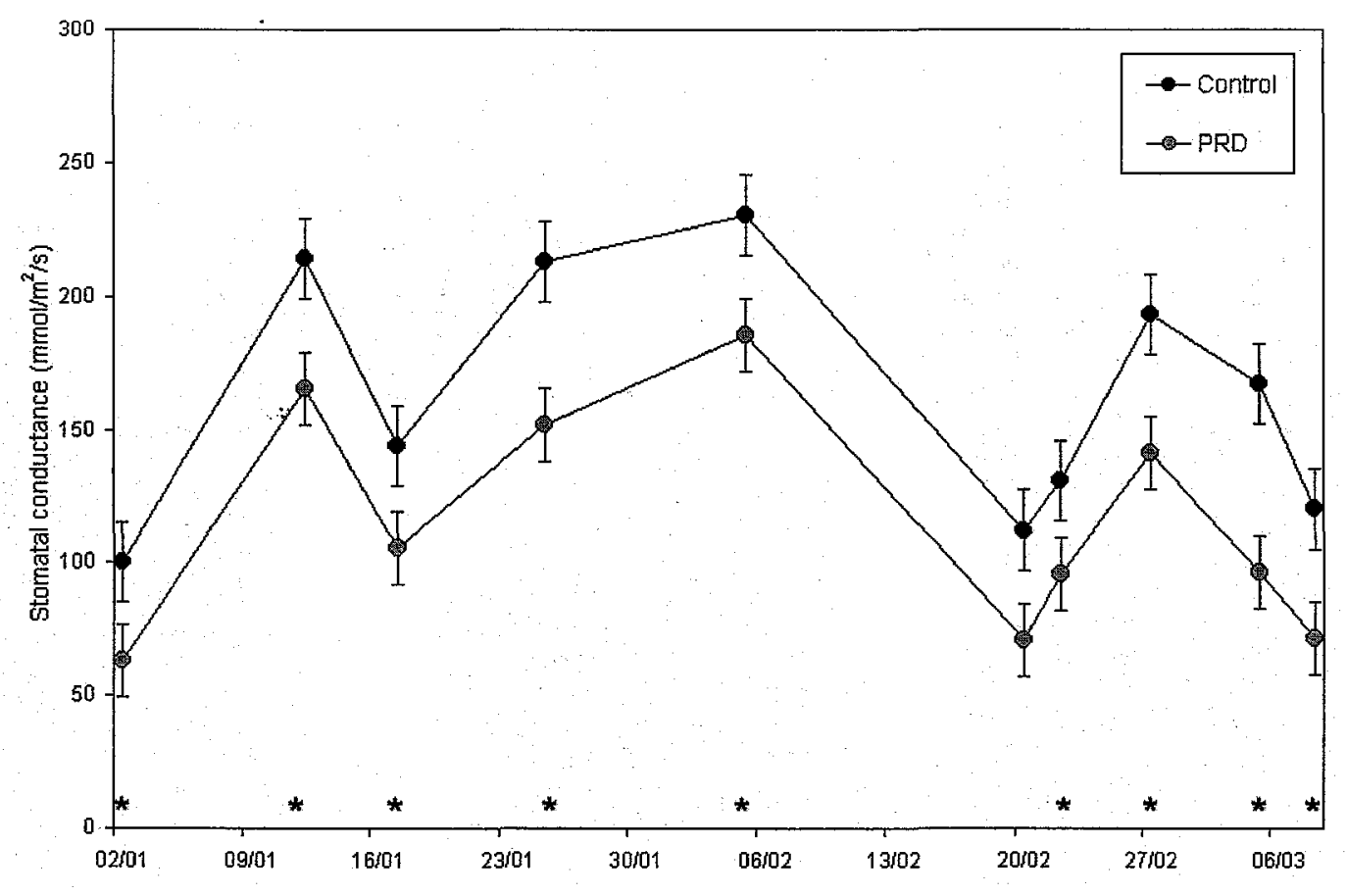

FIGURE 8

Stomatal conductance of Cabernet Sauvignon 2000/01 season). PRD received half the amount of water as control. Vertical bars indicate standard errors of the average. * $=$ significantly different $(\mathrm{P}<0.05)$. 


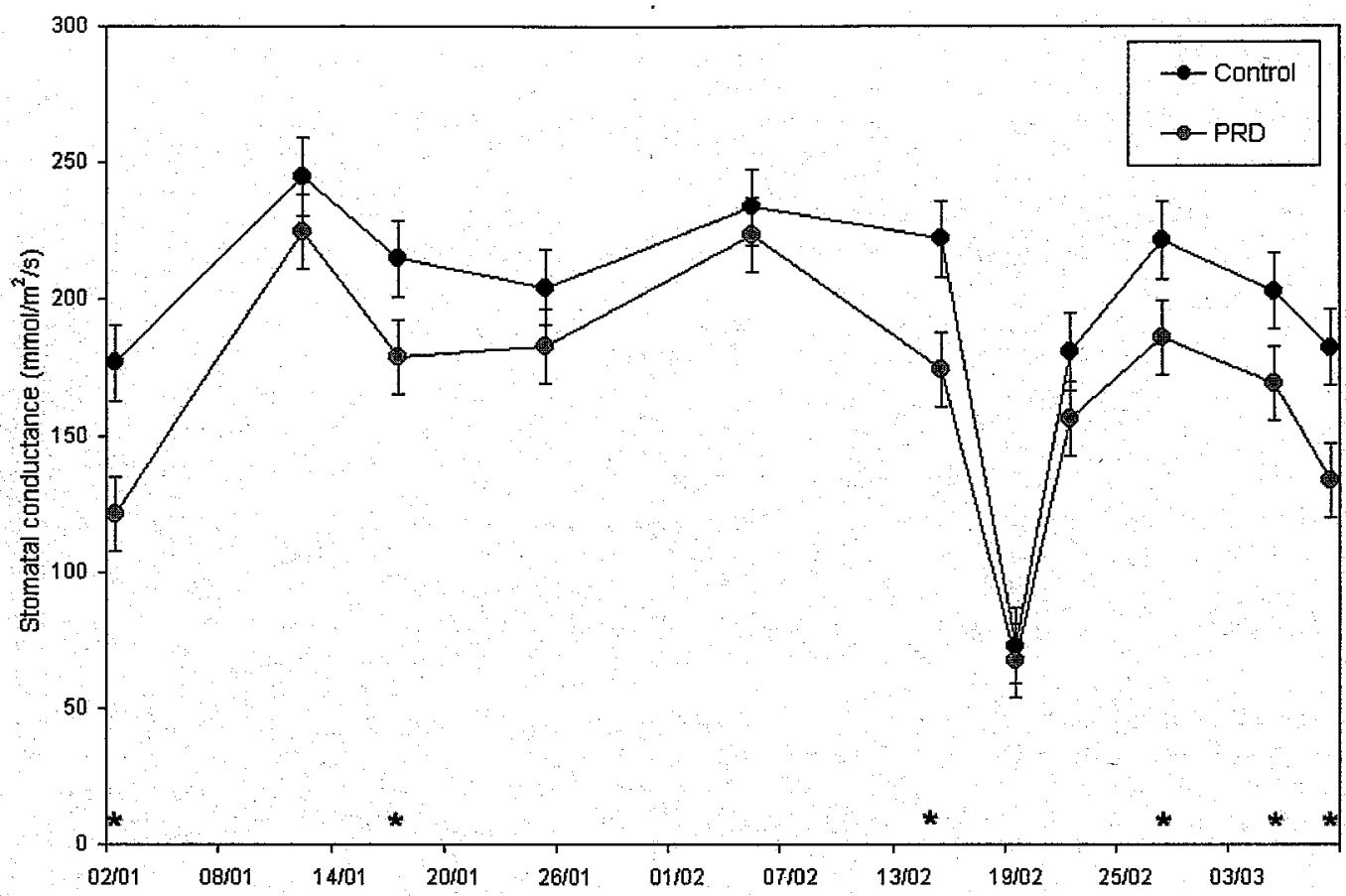

FIGURE 9

Stomatal conductance of Shiraz (2000/01 season). PRD received the same amount of water as control. Vertical bars indicate standard errors of the average. ${ }^{*}=$ significantly different $(\mathrm{P}<0.05)$.

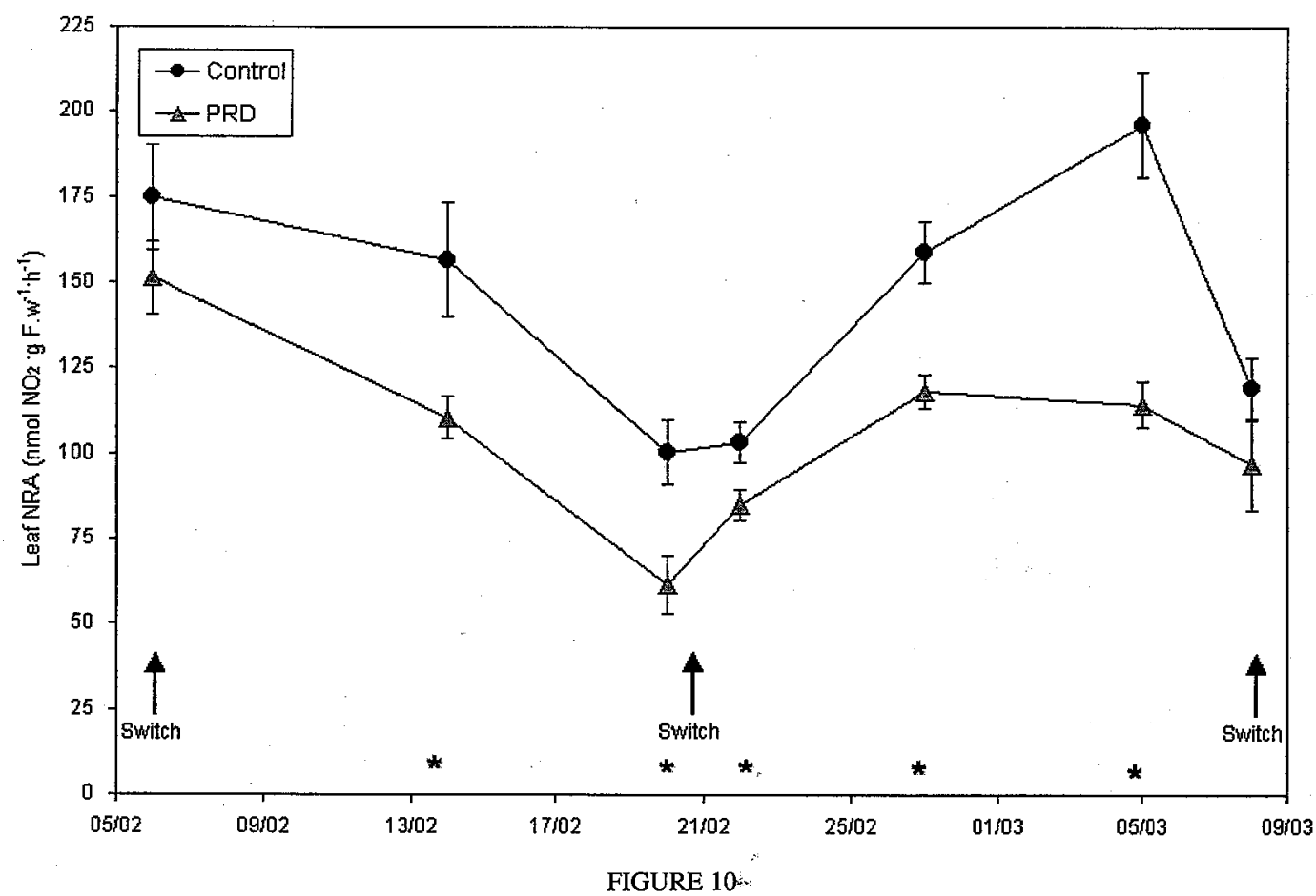

Effect of PRD on NR activity in leaves of field-grown Cabernet Sauvignon over one PRD cycle (PRD received half of control irrigation) measured during the $2000 / 01$ season. Vertical bars indicate standard errors of the average. $*=$ significantly different $(\mathrm{P}<0.05)$. so

An alteration of NR enzyme activity may be caused by both metabolic and environmental factors. Environmental factors aside, PRD may influence NR activity by changing substrate availability and/or by hormonal influences. It is hypothesised that the inhibition of NR in PRD grapevines may be due to one or more factors. Firstly, a reduction in Pn could have further far-reaching effects on NR activ- ity at the transcriptional and post-transcriptional level. $\mathrm{CO}_{2}$ removal from the atmosphere or stomatal closure in response to drought causes a rapid inactivation of leaf NR (Kaiser \& Förster, 1989). Secondly, because half of the root system is faced with a diminishing soil water content, nitrogen absorption of the roots may be decreased, thereby reducing NR activity because of its ability to be 


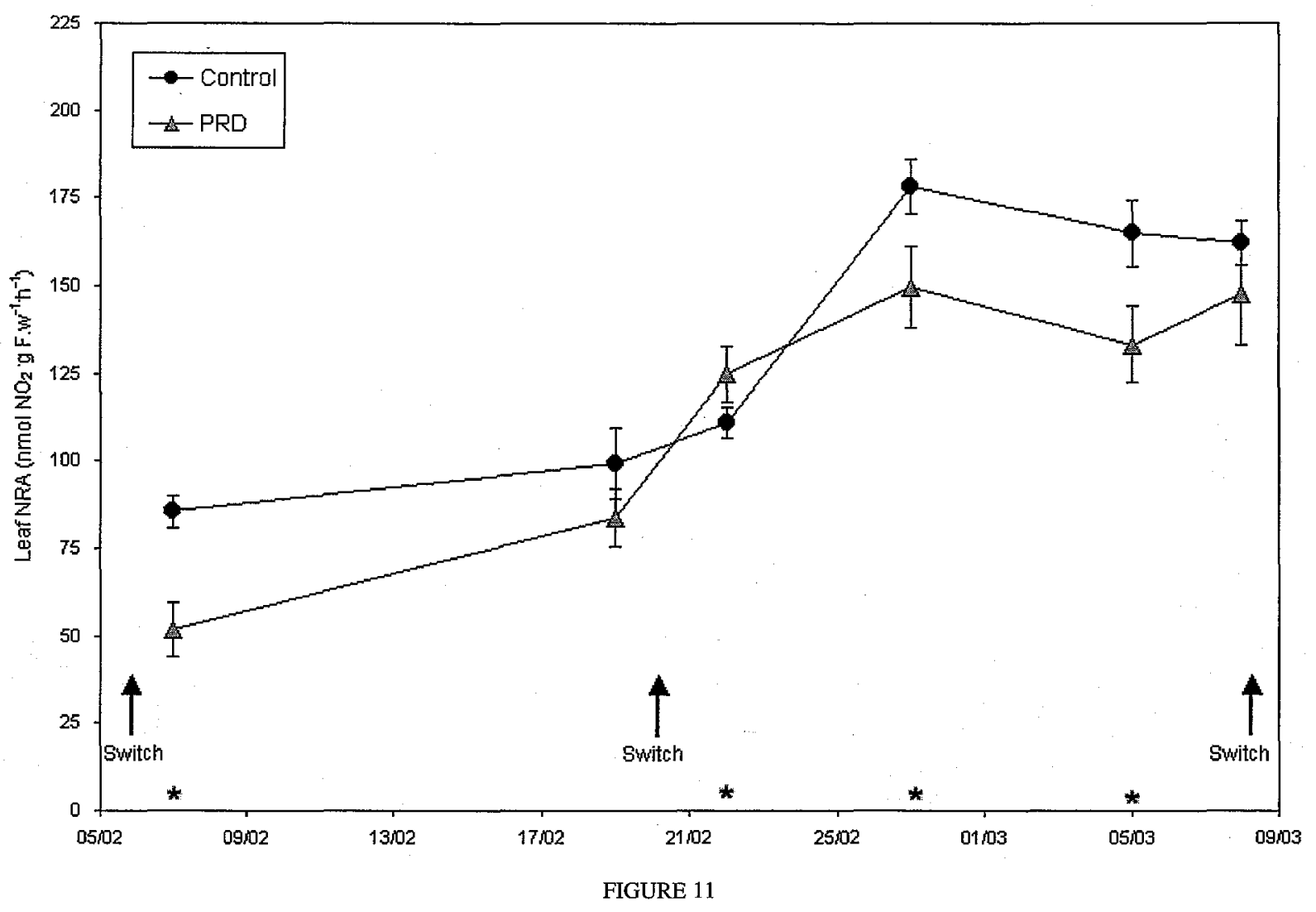

Effect of PRD on NR activity in leaves of field-grown Shiraz over one PRD cycle (PRD received the same amount as control irrigation) measured during the 2000/01 season. Vertical bars indicate standard errors of the average. * $=$ significantly different $(P<0.05)$.

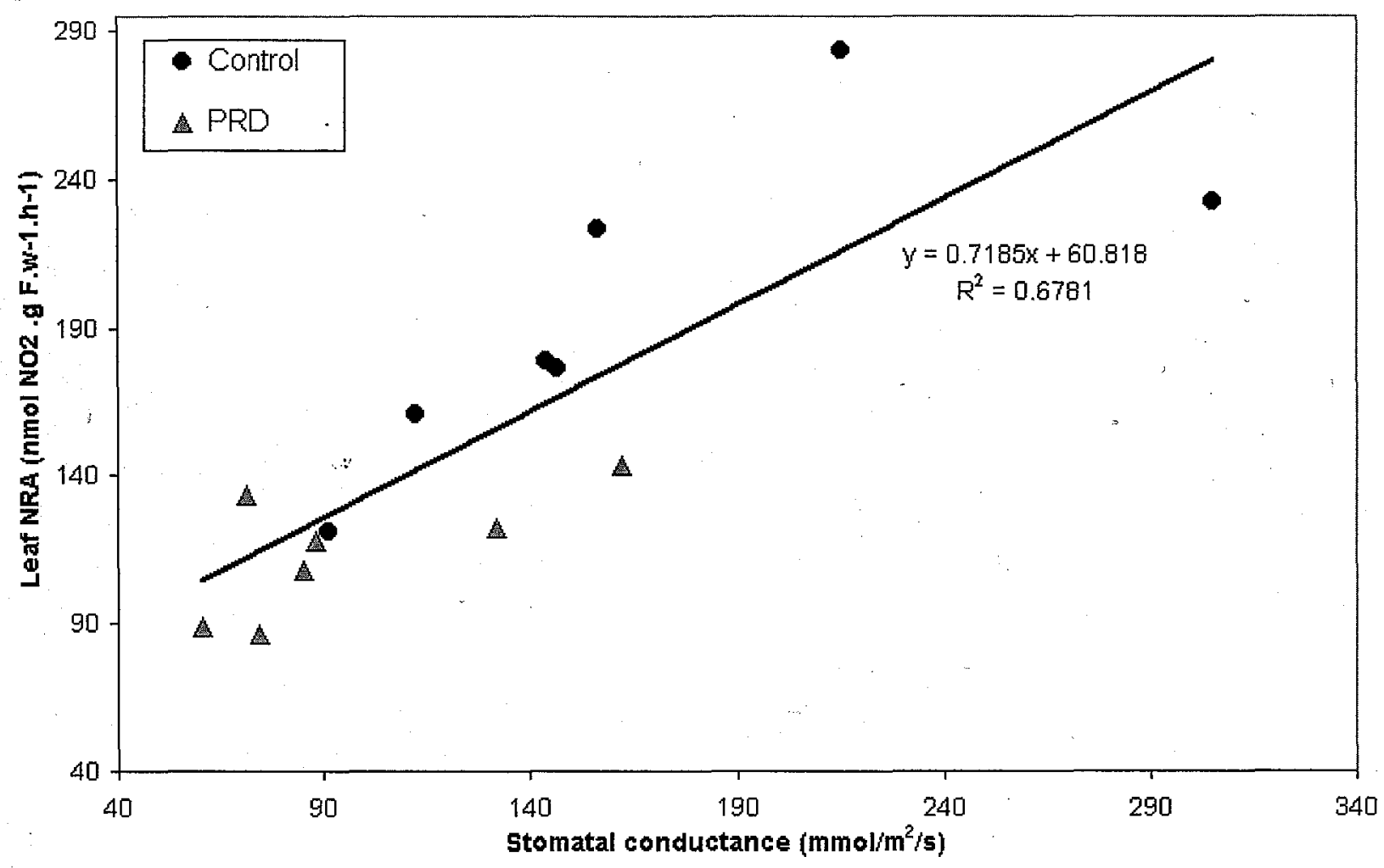

FIGURE 12

Relationship between leaf NR activity and stomatal conductance of field-grown Cabernet Sauvignon $(05 / 03 / 01)(\mathrm{P}=0.001)$. 


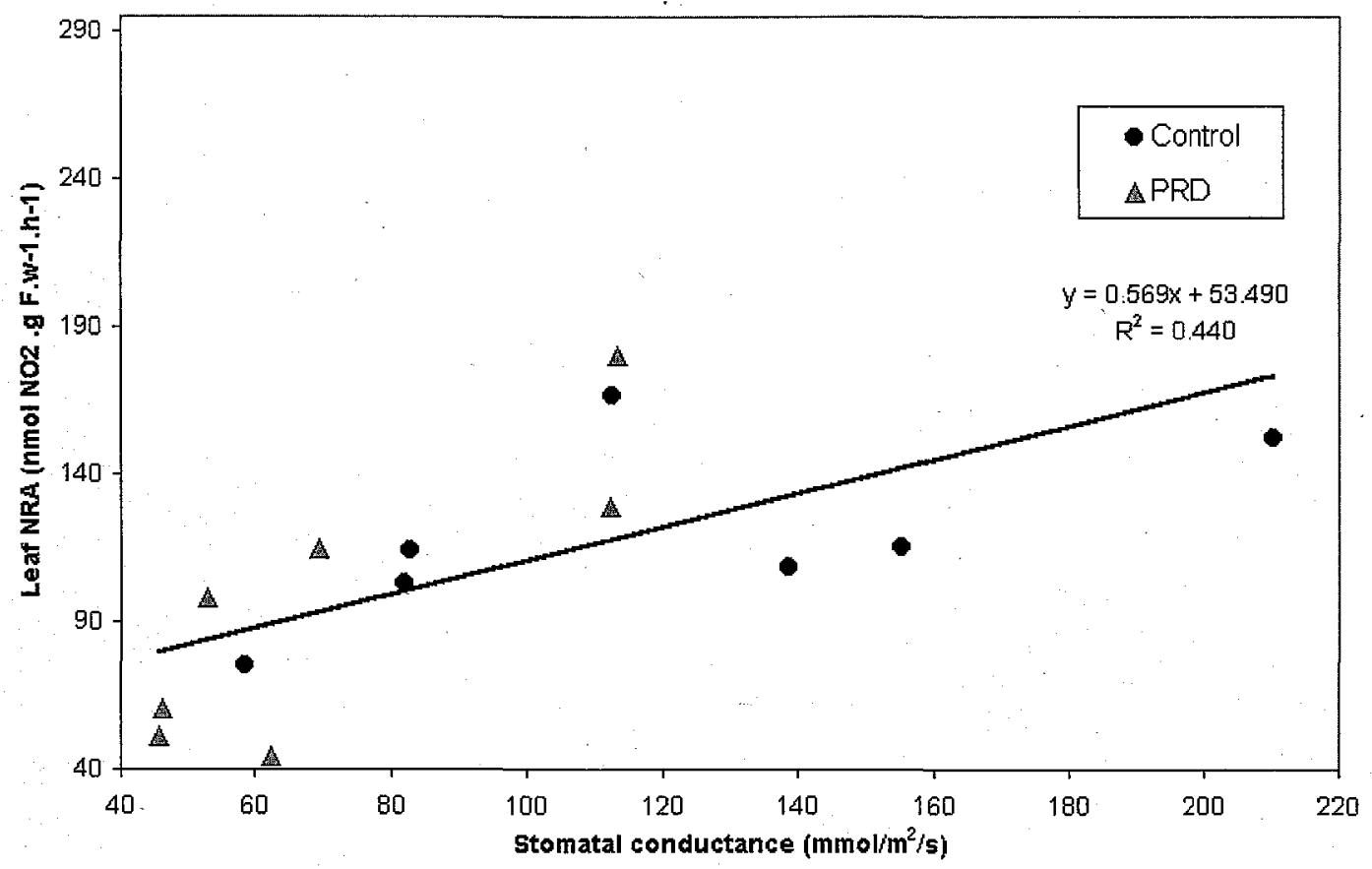

FIGURE 13

Relationship between leaf NR activity and stomatal conductance of field-grown Cabernet Sauvignon (08/03/01) ( $\mathrm{P}=0.114)$.

substrate-inducible (Gojon et al., 1991). In terms of root-to-shoot communication, nitrate itself is the primary signal molecule triggering the activation of transcription of nitrate assimilation and related genes (Takei et al., 2002). Furthermore, nitrogen availability could modulate cytokinin metabolism and translocation in higher plants (Takei et al., 2002). Therefore, in addition to nitrate, cytokinin could be a root-to-shoot signal communicating nitrogen availability. Thirdly, it is possible that NR activity may be directly influenced by the change in the ABA/cytokinin balance in PRD grapevines. The major phytohormone that influences NR is cytokinin (for a review see Gaudinova (1990)). NR activity is greatly increased in leaves in response to treatment with the cytokinin benzyladenine (BA) (Kende et al., 1971; Yu et al., 1998) and suppressed by ABA (Lu et $a l ., 1992)$. The NR mRNA levels are influenced by the BA/ABA concentration ratio and the inhibition of applied ABA can be only partially reversed by the application of equal concentrations of BA ( $\mathrm{Lu}$ et al., 1992). ABA concentration in roots and xylem sap, and delivery rate of $\mathrm{ABA}$ from xylem increases under mild water stress, while cytokinin supply from the roots may be significantly reduced by soil drying (Itai and Vaadia, 1965; Blackman and Davies, 1985; Abida et al., 1994; Shashidhar et al., 1996).

ABA elicits a variety of responses on NR activity in plant systems and this may explain why shoot growth is more sensitive to soil drying than root growth (Sharp \& Davies, 1989). At relatively high concentrations it reduces NR actixity in etiolated leaves of barley (Lu et al., 1992), potato (Palmer, 1985) and in Agrostemma githago (Kende et al., 1971). Conversely, ABA stimulated NR activity in root systems (Palmer, 1981; Chraibi et al., 1995; Goupil et al., 1998). This may be due to ABA increasing available reductants (Chraibi et al., 1995) that are less diverted to growth in shoots, favouring radial growth of roots under stress conditions, i.e. drought, compacted soil (Hürtung \& Davies, 1991; Vartanian et al., 1994). Goupil et al. (1998) and Chraibi et al. (1995) found that NR activity in roots, unlike shoots, was not related to intracellular $\mathrm{NO}_{3}$ concentration and not modulated by a phosphorylation/dephosphorylation mechanism. Palmer (1981), however, found that $\mathrm{ABA}$ stimulated root $\mathrm{NR}$ activity at low $\mathrm{NO}_{3}$ levels, while inhibiting $\mathrm{NR}$ activity at high $\mathrm{NO}_{3}$ levels. The inhibition of NR in PRD grapevine leaves indicates that the overall nitrogen assimilation process could be decreased and nitrogen partitioning influenced, which is in accordance with earlier findings of Stoll et al. (2000a) that PRD grapevines showed more exploratory root systems while shoot growth was reduced.

\section{CONCLUSIONS}

The PRD irrigation system is effective in reducing vegetative growth in grapevines while sustaining yield and grapevine health, thereby increasing water use efficiency. PRD affected both main shoot and lateral shoot growth, particularly the latter, irrespective of amount of water applied. Although berry size was not affected in Shiraz grapevines receiving the same amount of water, PRD Cabernet Sauvignon with half the amount of water had significantly smaller berries without a decrease in yield. Although it is uncertain if PRD was the main factor influencing berry size, smaller berries without a change in composition may produce wines with hî̀gher quality due to increased skin surface per unit berry mass. Berry composition was not influenced by PRD, suggesting that carbon accumulation or its partitioning towards berries was not detrimentally affected. PRD effects on grapevine shoot growth may be due to decreases in nitrogen assimilation as measured by the activity of NR. The PRD influence on leaf NR activity was found to be independent of amount of water applied. It is hypothesised that the observed reduction in NR activity may be influenced by either a reduced assimilation rate due to stomatal closure, a reduction in nitrogen absorption by roots and/or a hormonal influence. 


\section{LITERATURE CITED}

Abida, P. S., Sashidhar, V. R., Manju, R. V., Prasad, T. G. \& Sudharshana, L. 1994. Root-shoot communication in drying soil is mediated by the stress hormones abscisic acid and cytokinin synthesized in the roots. Current Science 66, 668-672.

Blackman, P. G. \& Davies, W. J., 1985. Root to shoot communication in maize plants of the effects of soil drying. J. Exp. Bot. 36, 39-48.

Chraibi, A., Palms, B., Druart, N., Goupil, P., Gojon, A. \& Rambour, S., 1995. Influence of abscisic acid on nitrogen partitioning, sucrose metabolism and nitrate reductase activity of chicory suspension cells. J. Exp. Bot. 46, 1525-1533.

Comstock, J. P., 2002. Hydraulic and chemical signalling in the control of stomatal conductance and transpiration. J. Exp. Bot. 53, 195-200.

Crawford, N. M. \& Glass, A. D. M., 1998. Molecular and physiological aspects of nitrate uptake in plants. Trends Plant Sci. 3, 389-395.

Davies, W. J., Bacon, M. A., Thompson, D. S., Sobeih, W. \& Rodriguez, L. G. 2000. Regulation of leaf and fruit growth in plants growing in drying soil: exploitation of the plants' chemical signalling system and hydraulic architecture to increase the efficiency of water use in agriculture. J. Exp. Bot. 51, 1617-1626

Davies, W. J., Tardieu, F. \& Trejo, C. L., 1994. How do chemical signals work in plants that grow in drying soil? Plant Physiol. 104, 309-314.

Davies, W. J. \& Zhang, J., 1991. Root signals and the growth and development of plants in drying soil. Ann. Rev. Plant Physiol. Plant Mol. Biol. 42, 55-76.

De Cires, A., De la Torre, A., Delgado, B. \& Lara, C., 1993. Role of light and $\mathrm{CO}_{2}$ fixation in the control of nitrate reductase activity in barley leaves. Planta 190 277-283.

Dry, P. R. \& Loveys, B. R., 1999. Grapevine shoot growth and stomatal conductance are reduced when part of the root system is dried. Vitis 38, 151-156.

Dry, P. R., Loveys, B. R. \& During, H., 2000. Partial rootzone drying of grape. I. Transient changes in shoot growth and gas exchange. Vitis 39, 3-7.

Dry, P. R., Loveys, B. R., McCarthy, M. G. \& Stoll, M., 2001. Strategic irrigation management in Australian vineyards. J. Int. Sci. Vigne. Vin. 35, 129-139.

Dundon, C. G. \& Smart, R. E., 1984. Effects of water relations on the potassium status of Shiraz vines. Am. J. Enol. Vitic. 35, 40-45.

Gaudinova, A., 1990. Effect of cytokinin on nitrate reductase activity. In: Kutacek M., Elliot, M. C. \& Machackova, M. (eds). Molecular aspects of hormonal regulation of plant development, Academic Publishing, The Hague. pp. 225-231.

Givan, C. V., 1979. Metabolic detoxification of ammonia in tissues of higher plants. Phytochemistry $18,375-382$

Gojon, A., Wakrim, R., Passama, L. \& Robin, P., 1991. Regulation of $\mathrm{NO}_{3}{ }^{-}$assimilation by anion availability in excised soybean leaves. Plant Physiology 96,398 405.

Goodwin, I. \& Jerie, P., 1992. Regulated deficit irrigation: from concept to practice. Advances in vineyard irrigation. Aust. NZ Wine Ind. J. 7, 258-261.

Goupil, P., Loncle, D., Druart, N., Bellettre, A. \& Rambour, S., 1998. Influence of ABA on nitrate reductase activity and carbohydrate metabolism in chicory roots (Cichorium intybus L.). J. Exp. Bot. 49, 1855-1862.

Hürtung, W. \& Davies, W. J., 1991. Drought-induced changes in physiology and ABA. In: Davies, W. (ed). Abscisic acid: physiology and biochemistry, Bios Scientific Publishers Ltd. pp. 63-75.

Huber, S. C., Huber, J. L., Campbell, W. H. \& Ređinbaugh, M. G., 1992. Apparent dependence of the light activation of nitrate reductase and sucrose phosphate synthase activities in spinach leaves on protein synthesis. Plant Cell Physiol. 33, 639646.

Hunter, J. J. \& Ruffner, H. P., 1997. Diurnal and seasonal changes in nitrate reductase activity and nitrogen content of grapevine: Effects of canopy management Vitis 36, 1-6

Itai, C. \& Vaadia, Y., 1965. Kinetin-like activity in root exudate of water-stressed sunflower plants. Physiologia Plantarum 18, 941-944.

Kaiser, W. M. \& Förster, J., 1989. Low $\mathrm{CO}_{2}$ prevents nitrate reduction in leaves. Plant Physiol. 91, 970-974.
Kende, H., Hahn, H. \& Kays, S. E., 1971. Enhancement of nitrate reductase activity by benzyladenine in Agrostemma githago. Plant Physiol. 48, 702-706.

Lewis, C. E., Noctor, G., Causton, D. \& Foyer, C. H., 2000. Regulation and assimilate partitioning in leaves. Aust. J. Plant Physiol. 27, 507-519.

Lin, C. C. \& Kao, C. H., 1996. Disturbed ammonium assimilation is associated with growth inhibition of roots in rice seedlings caused by $\mathrm{NaCl}$. Plant Growth Reg. 18, 233-238.

Litchfield, W. H., 1951. Soil survey of the Waite Agricultural Reseach Institute Glen Osmond, SA. CSIRO Australia Division of Soils Divisional Report. No. $2 / 51$

Loveys, B. R., Dry, P. R., Stoll, M. \& McCarthy, M. G., 2000. Using plant physiology to improve the water use efficiency of horticultural crops. Acta Hort. 537, 187-199.

Lu, J.-L., Ertl, J. R. \& Chen, C.-M., 1992. Transcriptional regulation of nitrate reductase mRNA levels by cytokinin-abscisic acid interactions in etiolated barley leaves. Plant Physiol. 98, 1255-1260.

Matthews, M. A. \& Anderson, M. M., 1988. Fruit ripening in Vitis vinifera L.: responses to seasonal water deficits. Am. J. Enol. Vitic. 39, 313-320.

Matthews, M. A. \& Anderson, M. M., 1989. Reproductive development in grape (Vitis vinifera L.): responses to seasonal water deficits. Am. J. Enol. Vitic. 40, 52 60

Naidu, B. P., 1998. Separation of sugars, polyols, proline analogues, and betaines in stressed plant extracts by high-performance liquid chromatography and quantification by ultra violet detection. Aust. J. Plant Physiol. 25, 793-800.

Oaks, A., Stulen, J., Jones, K., Winspear, M. J. \& Boosel, I. L., 1980. Enzymes of nitrogen assimilation in maize roots. Planta 148, 477-484

Palmer, C. E., 1981. Influence of abscisic acid on nitrate accumulation and nitrate reductase activity in potato tuber slices. Plant Cell Physiol. 22, 1541-1551.

Palmer, C. E., 1985. The relationship of abscisic acid on nitrate accumulation and nitrate reductase activity in potato tuber slices. Plant Cell Physiol. 26, 1167-1174.

Roubelakis-Angelakis, K. A. \& Kliewer, W. M., 1992. Nitrogen metabolism in grapevine. Horticultural Reviews 14, 407-452.

Scholander, P. F., Hammel, H. T., Bradstreet, D. \& Hemmingsen, E. A., 1965. Sap pressure in vascular plants. Science 148, 339-346.

Sharp, R. E. \& Davies, W. J., 1989. Regulation of growth and development of plants growing with a restrictive supply of water. In: Jones, H.G., Flowers, T.J. \& Jones, M.B. (eds). Plants under stress: biochemistry, physiology and ecology and their application to plant improvement, Cambridge University Press, New York pp. 71-93.

Shashidhar, V. R., Prasad, T. G. \& Sudharshan, L., 1996. Hormone signals from roots to shoots of sunflower (Helianthus anuus L.). Moderate soil drying increases delivery of abscisic acid and depresses delivery of cytokinins in xylem sap. Annals of Botany 78, 151-155.

Singleton, V. L., 1972. Effects on red wine quality of removing juice before fermentation to simulate variation in berry size. Am. J. Enol. Vitic. 23, 106-113.

Stoll, M., Dry, P., Loveys, B., Stewart, D. \& McCarthy, M., 2000a. Partial roo zone drying: Effects on root distribution and commercial application of a new irrigation technique. Wine Industry Journal 15, 74-77.

Stoll, M., Loveys, B. \& Dry, P., 2000b. Hormonal changes induced by partial rootzone drying of irrigated grapevine. J. Exp. Bot. 51, 1627-1634.

Takei, K., Takahashi, T., Sugiyama, T., Yamaya, T. \& Sakakibara, H., 2002 Multiple routes communicating nitrogen availability from roots to shoots: a signal transduction pathway mediated by cytokinin. J. Exp. Bot. 53, 971-977.

Vartanian, N., Marcotte, L. \& Giraudat, J., 1994. Drought rhizogenesis in Aridopsis thaliana. Plant Physiol. 104, 761-767.

Yu, X., Sukumaran, S. \& Marton, L., 1998. Differential expression of the Arabidopsis Nial and Nia2 genes. Plant Physiol. 116, 1091-1096.

Zhang, J. \& Davies, W. J., 1990. Changes in the concentration of ABA in the xylem sap as a function of changing soil water status can account for changes in leaf conductance and growth. Plant, Cell and Environment 13, 277-285. 